\title{
THE EFFECTS OF LEAD SOURCES ON ORAL BIOACCESSIBILITY IN SOIL AND IMPLICATIONS FOR CONTAMINATED LAND RISK MANAGEMENT
}

3

4

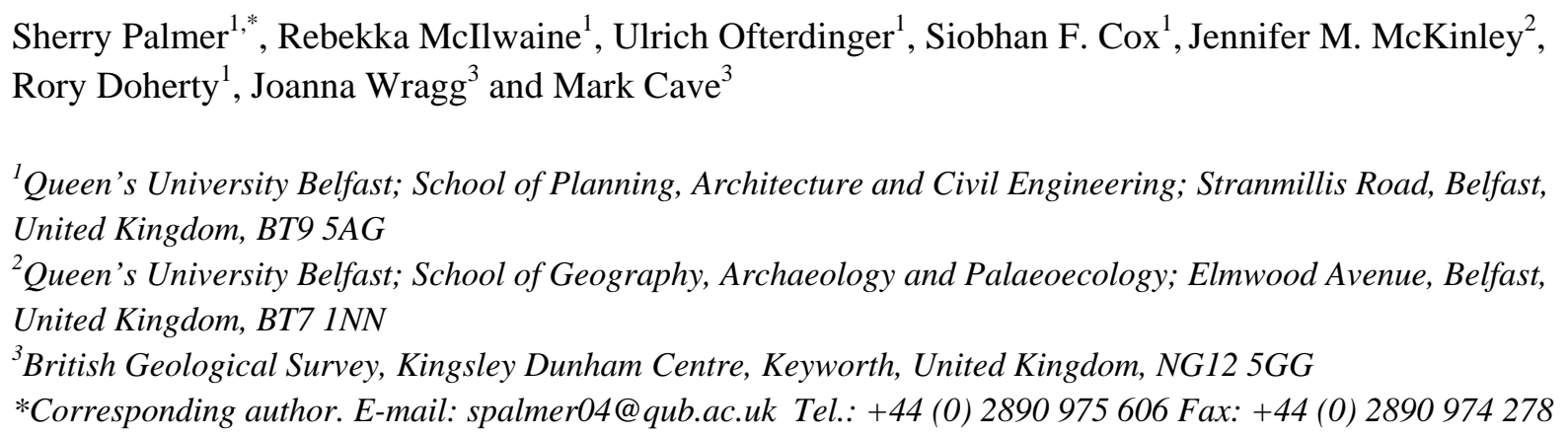

\section{Abstract}

Lead $(\mathrm{Pb})$ is a non-threshold toxin capable of inducing toxic effects at any blood level but availability of soil screening criteria for assessing potential health risks is limited. The oral bioaccessibility of $\mathrm{Pb}$ in 163 soil samples was attributed to sources through solubility estimation and domain identification. Samples were extracted following the Unified BARGE Method. Urban, mineralisation, peat and granite domains accounted for elevated $\mathrm{Pb}$ concentrations compared to rural samples. High $\mathrm{Pb}$ solubility explained moderate-high gastric $(G)$ bioaccessible fractions throughout the study area. Higher maximum G concentrations were measured in urban (97.6 mg kg${ }^{-1}$ ) and mineralisation (199.8 $\mathrm{mg} \mathrm{kg}$ ) domains. Higher average $\mathrm{G}$ concentrations occurred in mineralisation (36.4 $\mathrm{mg} \mathrm{kg}^{-1}$ ) and granite (36.0 mg kg $^{-1}$ ) domains. Findings suggest diffuse anthropogenic and widespread geogenic contamination could be capable of presenting health risks, having implications for land management decisions in jurisdictions where guidance advises these forms of pollution should not be regarded as contaminated land.

Keywords: lead, anthropogenic pollution, geogenic contamination, oral bioaccessibility, human health risk assessment, soil 
Lead $(\mathrm{Pb})$ is a toxic trace element that has been the subject of extensive human health research. Its neurotoxic effects from the oral exposure pathway, particularly in children, are well documented (EFSA, 2010; ATSDR, 2007; Ryan et al., 2004; CCME, 1999; Rosen, 1995). Some studies also suggest $\mathrm{Pb}$ exposure may be associated with increased incidences of violent crime (Meilke \& Zahran, 2012; Nevin, 2007; Nevin, 2000). Whilst many known toxins have quantifiable threshold exposure levels above which toxic health effects could occur, $\mathrm{Pb}$ is currently regarded by the global scientific community as a non-threshold toxin. Non-threshold toxicity indicates that laboratory studies have not identified a minimal risk level (MRL) or a no observed adverse effect level (NOAEL). Adverse health effects could potentially occur at any blood Pb level (EA, 2009; ATDSR, 2007; USEPA, 1988). Therefore, it is arguable that no amount of $\mathrm{Pb}$ exposure can be regarded as safe based on available research to date.

Elevated $\mathrm{Pb}$ in the environment is attributed to a number of human activities and industrial processes such as fuel combustion, mining, agricultural slurry spreading, and incineration of municipal wastes (Alloway, 2012; Nriagu \& Pacyna, 1989). The reported natural abundance of $\mathrm{Pb}$ in the earth's crust ranges from 12 -14 mg kg-1 (Rose et al., 1979; Lee \& Yao, 1970; Krauskopf, 1967; Taylor, 1964) although globally reported normal background concentrations (NBC) in soil can substantially vary. The United States Environmental Protection Agency (USEPA) suggests natural $\mathrm{Pb}$ concentrations in the United States range from 50 to $400 \mathrm{mg} \mathrm{kg}^{-1}$ (USEPA, 2013). The Canadian Council of Ministers of the Environment (CCME) provides a mean range of $12-25 \mathrm{mg} \mathrm{kg}^{-1}$ for Canadian Soils (CCME, 1999). The average reported concentration in rural soils in the United Kingdom (UK) is $52.6 \mathrm{mg} \mathrm{kg}^{-1}$, ranging from as low as 2.6 to as high as $713 \mathrm{mg} \mathrm{kg}^{-1}$ (EA, 2007). In Northern Ireland (NI), Jordan et al. (2001) reported a mean total $\mathrm{Pb}$ soil concentration of $23.2 \mathrm{mg} \mathrm{kg}^{-1}$. More recently, the Tellus Geochemical Survey of NI measured a higher average total $\mathrm{Pb}$ concentration of $41.7 \mathrm{mg} \mathrm{kg}^{-1}$, with a maximum extractable $\mathrm{Pb}$ concentration exceeding 3,000 $\mathrm{mg} \mathrm{kg}^{-1}$ near the Belfast metropolitan area. In rural parts of NI, McIlwaine et al. (2014) reported a typical threshold value (TTV) of $63 \mathrm{mg} \mathrm{kg}^{-1}$.

Due to the global variability in $\mathrm{Pb} \mathrm{NBCs}$ and also with regards to its non-threshold toxicity, identifying a starting point for contaminated land assessment in a human health context is challenging. The CCME provides a soil quality guideline of $140 \mathrm{mg} \mathrm{kg}^{-1}$ in a residential land use setting (CCME, 1999). Following its non-threshold toxicity classification, the generic $\mathrm{Pb}$ soil guideline value (SGV) (DEFRA \& EA, 2002a) was withdrawn in the UK. Whilst a selection of provisional Category 4 screening levels (pC4SL) for $\mathrm{Pb}$ were recently published (Harries et al., 2013), final C4SLs have not been issued for any soil contaminant. A C4SL denotes a lower tolerable limit for a contaminant in soil, beneath which human health risk is unlikely to be present. 
Although $\mathrm{Pb}$ concentrations in the wider environment have declined since its removal from petrol in the last century, its ubiquitous anthropogenic presence still persists in soils, particularly around urban centres (Harries et al., 2013; Appleton et al., 2012a). Previous research worldwide has highlighted areas of elevated soil $\mathrm{Pb}$ concentrations outside of areas where geogenic associations are known to exist, including within the Republic of Ireland (ROI) and NI (Barsby et al., 2012; Bourennane et al., 2010; Jordan et al., 2007; Ljung et al., 2006; Zhang, 2006). Such findings demonstrate how anthropogenic pollution sources substantially contribute to elevated soil $\mathrm{Pb}$ concentrations. In NI Pb is found in highest total and extractable concentrations around the Belfast urban area and in soils overlying mineral deposits, with high soluble $\mathrm{Pb}$ measured in peaty upland areas (Jordan et al., 2001). This latter observation may be accounted for by atmospheric deposition of anthropogenic $\mathrm{Pb}$ through rainfall, as precipitation is the primary moisture source in upland peat soils.

The large surface area and number of acidic functional groups that are common to peat make it an ideal substrate to bind trace elements either as sedimentary, deposited, particulate matter or as sorbed or complexed metal ions (Brown et al., 2000). The major sources of metals in the peat mass of ombrotrophic peat bogs has been shown to come from atmospheric precipitation (Steinnes and Friedland, 2006) which has been specifically illustrated in Ireland (Coggins et al., 2006). Whilst the ability of peat to accumulated trace metals has been well documented there is little data on the bioaccessibility of the trace elements in this peat rich soils.

Four $\mathrm{Pb}$ source domains were previously identified in NI accounting for elevated soil $\mathrm{Pb}$ concentrations (McIlwaine et al., 2014). A domain is an area where a distinguishable factor is recognised as controlling the concentration of an element. Urban, peat, granite and mineralisation $\mathrm{Pb}$ source domains were related to elevated concentrations of Pb, with typical threshold values (TTV) higher than the TTV calculated for the remaining rural domain. TTVs aim to identify the threshold between diffuse and point source anthropogenic contamination, thereby giving an indication of typical concentrations within defined geographical areas. Urban $\mathrm{Pb}$ source domains are likely to be directly attributable to anthropogenic activity. Some anthropogenic pollution sources are potentially more soluble in the environment and resultantly more bioavailable (Ljung et al., 2007; Appleton et al., $2012 b$ ), in turn posing a greater risk to human health.

Not all toxins that are rendered bioaccessible will be bioavailable, but in vitro bioaccessibility tests can better refine the contaminated land risk assessment process by reducing reliance on total soil contaminant concentrations. Such reliance may overestimate health risks (CIEH, 2009; Scheckel et al., 2009; Nathanail \& Smith, 2007; Nathanail, 2006; Ruby et al., 1999). The Unified BARGE (Bioaccessibility Research Group of Europe) Method (UBM) is therefore a useful extraction method to employ in risk assessment scenarios where oral contaminant exposure is expected to contribute to toxic health effects. The UBM is a robust soil extraction technique that measures in vitro the oral 
bioaccessibility of contaminants by mimicking the conditions of the human stomach and upper intestine (BARGE/INERIS, 2010). The method has been validated for Pb, arsenic (As) and cadmium 115 (Cd) using in vivo swine data (Denys et al., 2012; Caboche, 2009) and has also been subjected to global inter-laboratory trials (Wragg et al., 2011). Data obtained from UBM extractions provide an indication of what fraction of a contaminant may be solubilised in the gastro-intestinal (GI) tract (the bioaccessible portion) and therefore potentially available for absorption resulting in toxic health effects (the bioavailable portion).

The aim of this research was to measure the oral bioaccessibility of $\mathrm{Pb}$ in soil and attribute findings to different $\mathrm{Pb}$ sources through solubility estimation and source domain identification. This aim was met through 1) exploratory geochemistry data analysis (EDA) to identify areas of elevated soil $\mathrm{Pb}$ concentrations and examine associated spatial structures, 2) comparison of total and extractable $\mathrm{Pb}$ concentrations to estimate $\mathrm{Pb}$ solubility and 3) source domain identification to determine whether elevated $\mathrm{Pb}$ concentrations are the result of geogenic or anthropogenic processes. Lastly, measured oral bioaccessibility was compared across the identified $\mathrm{Pb}$ source domains.

\section{Methodology and Study Area}

\subsection{Study Area}

The study area is located in the UK and Ireland, consisting of NI and neighbouring County (Co.) Monaghan in ROI (Fig. 1). The estimated cumulative population of NI and Co. Monaghan is 1.9 million, with a low average population density of 130 per km² (ONS, 2013; CSO, 2011). Current and historical industrial activities concentrated around the Belfast metropolitan area include textiles manufacturing, shipbuilding and aerospace engineering. In addition, quarrying activities are widespread throughout the region with active mines also present, particularly near the Antrim Glens in the northeast (GSNI, 2014). Outside of the larger urban areas of Belfast and Londonderry, land is largely rural and used for agricultural purposes, with metropolitan areas accounting for less than $4 \%$ of land use across the study area (European Environment Agency, 2012). As a result, the study area is perceived to be relatively unspoiled from an anthropogenic pollution perspective (Zhang, 2006).

Soil types present in the study area include peats, humic and sand rankers, brown earths, podzols, mineral gleys and alluviums. Soil $\mathrm{pH}$ falls within a narrow acidic range of approximately 5.0 to 6.0 (Jordan et al., 2001), with the NI Tellus geochemical survey more recently recording an average $\mathrm{pH}$ of 4.7. This decrease in $\mathrm{pH}$ over time suggests acidification of soils may be increasing in the study area. The climate is temperate and average annual rainfall ranges from a low of $800 \mathrm{~mm}$ in the eastern region to a high of over $1900 \mathrm{~mm}$ in the west. The Antrim Glens in the northeast, the Sperrin 
Mts. in the west and the granitic Mourne Mts. in the southeast intercept much of the precipitation borne by air currents which have travelled over the Atlantic Ocean, although the western half of the study area is most significantly affected by these Atlantic weather patterns (Met Office, 2012).

\subsection{Geochemistry Data Analysis}

Total and extractable $\mathrm{Pb}$ concentration data from the NI Tellus and Tellus Border geochemical surveys were provided by the Geological Survey of Northern Ireland (GSNI) and by the Geological Survey of Ireland (GSI), respectively. Rural NI Tellus Survey soil samples were collected on a $2 \mathrm{~km}^{2}$ grid at depths of $5-20 \mathrm{~cm}$ ('A') and $35-50 \mathrm{~cm}$ ('S'). 'A' samples were analysed for total $\mathrm{Pb}$ concentrations by x-ray fluorescence spectrometry (XRFS) and for extractable concentrations by inductively coupled plasma mass spectrometry (ICP-MS) following an aqua regia digest. 'S' NI Tellus Survey soil samples were also digested by aqua regia and analysed by ICP-MS. Tellus Border 'A' samples were collected on a $4 \mathrm{~km}^{2}$ grid and analysed only by ICP-MS following an aqua regia digest to yield extractable concentration data. Full analytical and field methods employed by these comprehensive regional geochemical surveys can be found in Smyth (2007) and Knights and Glennon (2013).

As part of this research, additional XRFS analysis was conducted at the British Geological Survey (BGS) Analytical Geochemistry Facility on a sub-set of 18 Tellus Border 'A' samples in Co. Monaghan according to the same methods described in the NI Tellus Survey methodology (Smyth, 2007). The additional XRFS data was required for solubility estimation and for calculation of UBM bioaccessible fractions (BAF) in Co. Monaghan. Geochemistry data were handled in SPSS v.19.0, R (R Core Team, 2013) and MS Excel 2010.

\subsection{Geostatistical Analysis and Interpolation}

Interpolation by ordinary kriging (OK) (Matheron, 1965) was conducted in ArcMap 10.0 (ESRI, 2010). The OK model yielding a mean prediction error closest to zero was selected as the final model for generating interpolated surfaces and geostatistics (Lloyd, 2010). Geostatistical outputs can be influenced by a nonparametric data distribution (Lloyd, 2010; Clarke, 2001; Einax \& Soldt, 1999). Total and extractable $\mathrm{Pb}$ concentration data were therefore log-transformed prior to interpolation. $\mathrm{OK}$ models were checked for robustness using cross validation statistics and a visual assessment of the best fit semi-variogram using a maximum search neighbourhood of 12 nearest sample locations. 
Semi-variogram parameters give an indication of the spatial structure that exists within a data set. This in turn can help explain geochemical or environmental processes that affect the spatial distributions of elements (Goulard \& Voltz, 1992; McBratney et al., 1982). The semi-variogram sill $\left(C_{1}\right)$ is synonymous with the sample variance and represents the maximum variance that exists between measured sample values within the range of spatial correlation (a). Beyond the distance $a$, samples are no longer spatially correlated (Clarke, 2001; Gringarten \& Deutsch, 2001). The nugget variance $\left(C_{0}\right)$ is attributed to micro-scale variance outside of sampling resolutions. Although the nugget effect is commonly regarded as an indication of measurement error or random semi-variogram behaviour, micro-scale processes which control element distributions may also be accounted for by the nugget variance. For example, Imrie et al. (2008) found that factors attributed to anthropogenic land use patterns were accounted for by a nugget effect. Dobermann et al. (1995) concluded buffalo excrement influenced soil chemistry over a range that occurred within the nugget variance. Functions with a high proportion of total variance $\left(C_{o}+C_{1}\right)$ accounted for by the nugget variance may therefore be indicative of anthropogenic processes or land use behaviours which are significantly affecting element distributions but occurring over short spatial scales not detected by the primary range $(a)$ of the function.

OK yields results which increase in accuracy in line with increasing sample numbers (Einax \& Soldt, 1999). Due to lower sample numbers than were available for total and extractable $\mathrm{Pb}$ concentration data, bioaccessible $\mathrm{Pb}$ concentrations were interpolated using inverse distance weighting (IDW) with a maximum search neighbourhood of five neighbouring sample locations. IDW is an exact interpolator (Lloyd, 2010) and this method therefore yielded a more accurate range of $\mathrm{Pb}$ bioaccessible concentration values across the interpolated surface.

\subsection{Pb Solubility Estimation}

A method for estimating element solubility in soil at a regional scale was applied to the NI Tellus and Tellus Border XRFS and ICP-MS data, similar to approaches used previously in Finland (Jarva et al., 2009) and Cyprus (Cohen et al., 2012). XRFS measures total element concentrations in soils whereas ICP concentrations rely on the antecedent aqua regia acid extraction. Although aqua regia acid is said to effectively leach many metals (Gill, 1997), the solubility of elements will affect how easily they are leached from the soil (Delgado et al., 2011). Therefore, by comparing the concentrations measured by the two methods, element solubility at a regional scale can be estimated. Elements which are more soluble in the environment generally exhibit higher oral bioaccessibility (Finžgar et al., 2007). 
ICP extractable concentrations were plotted against XRFS total concentrations using the R statistical software package (R Core Team, 2013) to explore the relationship between the two analytical methods. The ratio of XRFS/ICP Pb concentrations was mapped by OK to illustrate geographical trends in $\mathrm{Pb}$ solubility. The classes on the map were defined by the boxplot classes method (McIlwaine et al., 2014) with an additional class added where the ratio was equal to one, i.e. where the two analytical methods are equal. Boxplot classifications retained the appropriate amount of detail to allow a direct comparison with the mapped bioaccessibility results.

\subsection{Pb Domain Identification}

Domains were previously identified for Pb in NI as described in McIlwaine et al. (2014). Total XRFS concentrations in shallow soils were mapped using empirical cumulative distribution function (ECDF) classes and compared to the main factors identified as controlling element concentrations-bedrock geology, superficial geology, land use classification and mineralisation. Elevated concentrations of $\mathrm{Pb}$ were attributed to urban, granite, mineralisation and peat source domains in NI with the remaining rural domain hosting lower $\mathrm{Pb}$ concentrations.

Additional Co. Monaghan data were obtained to identify Pb domains across the extent of the study area for this research. Bedrock geology data were obtained from the GSI 1:500000 Bedrock Geology map (GSI, 2005). Superficial peat cover was identified using the Irish Environmental Protection Agency Soils and Subsoils Mapping Project data completed by Teagasc (Fealy \& Green, 2009). The Corine land cover data (European Environment Agency, 2012) was used to identify urban and rural land use within the study area. Areas of known or suspected mineralisation in Co. Monaghan are identified in the Tellus Border prospectivity map (Coulter and Stinson, 2013).

Data used for identifying the mineralisation source domain in NI and Co. Monaghan relied upon prospectivity maps (Coulter \& Stinson, 2013; Lusty et al., 2012) and not the locations of working or historic mines. The mineralisation domain and associated soil $\mathrm{Pb}$ is therefore regarded as geogenic and naturally occurring for the purposes of this research.

\subsection{Oral In Vitro Bioaccessibility Testing}

UBM extractions were carried out in 2009 (Barsby et al., 2012) and 2013 at the BGS Analytical Geochemistry Facility following the published method (BARGE/INERIS, 2010). The 2009 and 2013 data sets were joined to create a UBM data set of 163 samples for this research. Samples $(<2 \mathrm{~mm}$ 
fraction) were selected from the NI Tellus Survey and Tellus Border soil archives to cover a wide range of soil and underlying bedrock types present in the study area.

Standard BGS internal laboratory procedures were followed during UBM extraction and analysis according to UK Accreditation Service national laboratory requirements. Reagents were sourced by BGS from Merck, Sigma, Baker and Carl Roth. Saliva, gastric, duodenal and bile solutions were prepared one day prior to soil extractions to permit stabilisation. Solution $\mathrm{pH}$ was adjusted as required according to UBM specifications using either $37 \% \mathrm{HCl}$ or $1 \mathrm{M} \mathrm{HNO}_{3}$ (Table 1). Soils not adhering to $\mathrm{pH}$ specifications $(\mathrm{pH}<1.5)$ after one hour of gastric extraction were discarded and reextracted at a later date.

Extracts were analysed by an Agilent 7500cx series ICP-MS employing an octopole reaction system in combination with a CETAC autosampler. The instrument was calibrated at the beginning of every analytical run using a minimum of three standards and one blank for each trace element. Multielement quality control check standards were analysed at the start and end of each run and after every 25 samples at minimum.

One blank, one duplicate and one certified BGS102 reference soil (Wragg, 2009) were included in the extraction run for each of seven soils extracted in 2013. The BGS102 certificate of analysis provides certified UBM values for acceptable ranges of gastric $(\mathrm{G}) \mathrm{Pb}$ concentrations. Average measured $\mathrm{G} \mathrm{Pb}$ in reference soils was within one standard deviation of the certified BGS102 value. The mean relative per cent difference (RPD) for gastric $\mathrm{Pb}$ in study area soil samples was $8 \%$. In line with the available BGS102 certified reference value for $\mathrm{G} \mathrm{Pb}, \mathrm{G}$ data are presented in the following results as it is common practice to report the results yielding the highest bioaccessibility to ensure health risks are not underestimated. This approach also adheres to the precautionary principle advocated by UK contaminated land legislation and guidance (DEFRA, 2012). Details of quality control for 2009 extractions are similar to the above and are described in detail in Barsby et al. (2012).

\section{Results}

\subsection{Lead Soil Concentrations}

The highest extractable $\mathrm{Pb}$ concentrations are found in soils along the northeast coast near the Antrim Glens, extending south into the Belfast metropolitan area and Ards Peninsula, with the occurrence of elevated Pb concentrations continuing along the southeast NI-Co. Monaghan border (Fig. 1, Fig. 2A). Peat soils overlying the Sperrin Mts. in the northwest also host elevated concentrations of $\mathrm{Pb}$. It is this part of the study area that receives the most precipitation borne from Atlantic Ocean air currents 
290 (Met Office, 2012). The maximum measured extractable $\mathrm{Pb}$ concentration occurs near the greater

291 Belfast metropolitan area (> $\left.3000 \mathrm{mg} \mathrm{kg}^{-1}\right)$.

292

293 Although no SGV is currently available for $\mathrm{Pb}$ in the UK, Table 2 provides an overview of how $\mathrm{Pb}$ 294 concentrations compare against historic withdrawn and current provisional soil screening criteria. 295 Fig. 2B illustrates where extractable Pb concentrations exceed the lowest published pC4SL of $30 \mathrm{mg}$ $296 \mathrm{~kg}^{-1}$ by at least $10 \%$. This criterion is applicable for a female child in an allotment setting (Harries et 297 al., 2013). Pb concentrations were flagged as exceeding the pC4SL only where the concentration met or exceeded $33 \mathrm{mg} \mathrm{kg}^{-1}$ to ensure the measured $\mathrm{Pb}$ concentration was sufficiently above the pC4SL.

299 Extractable Pb concentrations exceed the pC4SL at over 2,208 of 7,234 NI Tellus and Tellus Border 300 soil sample locations in the study area (Fig. 2B). When total XRFS Pb concentrations are compared 301 with the pC4SL, the number of occurrences where the screening criterion is exceeded increases to 2,629 (not illustrated).

303

Given the withdrawn and provisional nature of the Pb SGV and pC4SL, respectively, it would not be possible to assess the potential level of health risk from the values presented in Table 2 and Figs. 2A$\mathrm{B}$ alone. Although Fig. 2B shows a geographically widespread occurrence of extractable $\mathrm{Pb}$ concentrations exceeding the lowest published pC4SL, it is important to note that individual sites must be assessed on a case by case basis taking relevant land use scenarios and all likely risk exposure pathways into account.

XRFS Pb concentrations were mapped previously by Barsby et al. (2012) and exhibit similar spatial patterns to extractable $\mathrm{Pb}$ concentrations. Extractable $\mathrm{Pb}$ concentrations are controlled by a spatial function with a moderate range (a) of $22.8 \mathrm{~km}$. Short to medium range spatial functions are sometimes associated with processes that have a higher frequency of variation over short distances. Such functions can be the result of smaller scale processes such as anthropogenic interactions with the environment, while long range functions capture the effects of larger scale geologic forming processes (Imrie et al., 2008; Dobermann et al., 1995). Pb exhibits a spatial structure in the study area that varies over a short scale in terms of its range relative to trace elements of known geogenic origin such as nickel or chromium which are controlled by longer range functions (>70 km; McIlwaine et al., 2014; Barsby et al., 2012). The high proportion of nugget variance (63\%) for Pb spatial distributions (Table 3) also suggests a high degree of micro-scale variation or spatial variability not detected by the primary range of the $\mathrm{Pb}$ function. Fig. 3 illustrates the difference between Pb extractable concentrations in NI Tellus Survey 'A' soils and ' $\mathrm{S}$ ' soils as measured by ICP-MS following an aqua regia digest. $\mathrm{Pb}$ is present at higher average 
and maximum concentrations in ' $\mathrm{A}$ ' soils than ' $\mathrm{S}$ ' soils. Anthropogenic and atmospheric $\mathrm{Pb}$ deposition to soil is expected to be most pronounced at surface level ('A').

\subsection{Lead Solubility and Domain Identification}

Figs. 4 and 5 illustrate comparative differences in $\mathrm{Pb}$ extractable and total concentrations. Such information can provide insight into contaminant sources. For example, geogenic metals are often highly insoluble and exhibit lower bioaccessibility (Cox et al., 2014) whilst other forms of anthropogenic pollution tend to be more soluble and more bioaccessible (Ljung et al., 2006).

Fig. 4 plots the relationship between XRFS and ICP Pb concentrations, with a 1-1 ratio represented by the dashed line shown on the scatterplot. Although soil analysis by XRFS detects an additional insoluble portion of $\mathrm{Pb}$, the cluster of most points around the 1-1 line shows that a significant proportion of total $\mathrm{Pb}$ soil concentrations was detectable by ICP, with XRFS concentrations exceeding ICP concentrations by no more than $15 \%$. This suggests the majority of $\mathrm{Pb}$ in soil is soluble and not encapsulated by an insoluble mineral matrix. $\mathrm{Pb}$ encapsulated by insoluble minerals generally displays decreased bioavailability and bioaccessibility (Ruby et al., 1999).

Fig. 5 illustrates the geographic variability in XRFS/ICP concentrations ratios. Higher levels of $\mathrm{Pb}$ solubility occur in the darker areas of the map, where the ratio is less than one. Where the map becomes lighter $\mathrm{Pb}$ is less soluble. Higher levels of solubility are observed along the central and western NI-ROI border and throughout the eastern coast. One area of higher solubility strongly aligns with an identified mineralisation source domain (Fig. 6A). Higher proportions of insoluble Pb occur in the southeast and northwest near the Mourne and Sperrin Mts., respectively, with the Mourne Mts. comprising the granite source domain and the Sperrin Mts. and associated geology aligning with the peat source domains. Rural, peat and urban domains host moderately soluble portions of $\mathrm{Pb}$. Although an elevated peat source domain was also identified in Fig. 6A, Pb solubility trends in Fig. 5 do not clearly align spatially with patterns illustrated for the peat source domain. Instead Pb solubility in peat is comparable to the intermediate solubility observed within urban source domains.

\subsection{Lead Bioaccessibility}

The results of UBM extractions are summarised in Table 4. G bioaccessibility was higher than gastro-intestinal (GI) bioaccessibility due to the lower $\mathrm{pH}$ of the $\mathrm{G}$ digestion which increases $\mathrm{Pb}$ mobility in solution (Denys et al., 2012; Farmer et al., 2011; Denys et al., 2007). The maximum G bioaccessible concentration was $199.8 \mathrm{mg} \mathrm{kg}^{-1}$, accounting for $68.6 \%$ of total Pb. The median G ICP- 
BAF was $40.3 \%$, decreasing to $15.6 \%$ of extractable $\mathrm{Pb}$ concentrations in the GI phase. XRFS-BAF values $\mathrm{Pb}$ did not differ greatly from ICP-BAFs as a result of most $\mathrm{Pb}$ in soils in the study area being detectable by ICP-MS (Fig. 4). Pb gastric bioaccessibility exceeded 50\% of total concentrations at 13 different soil locations across the study area (Fig. 6A).

Fig. 6A and Table 5 compare elevated $\mathrm{Pb}$ source domains with measured gastric oral bioaccessibility. Across the five source domains (inclusive of the rural domain), the mean ICP-BAF range was 35.6\% 46.4\%. The highest maximum BAFs and the highest mean and maximum bioaccessible concentrations occurred in the mineralisation domain. Despite insoluble portions of $\mathrm{Pb}$ observed near the granite domain (Fig. 5), the highest average BAFs were measured in soils overlying this domain. Rural areas had the lowest mean and minimum bioaccessible $\mathrm{Pb}$ concentrations and the lowest average BAFs (Table 5). Urban domains accounted for the second highest maximum bioaccessible $\mathrm{Pb}$ concentrations, although peat and urban domains each hosted intermediate levels of bioaccessible $\mathrm{Pb}$ in general when compared to the other source domains (Table 5). Where small urban domains overlapped with the extent of the mineralisation domain, it was assumed mineralisation acted as the primary $\mathrm{Pb}$ source and samples were assigned to the mineralisation domain.

Despite the lower solubility of $\mathrm{Pb}$ in soils overlying the Sperrin Mts. (Fig. 5), $\mathrm{Pb}$ from the peat source domain present in this area is still moderately bioaccessible (Fig. 6A, Table 5). Similarities in $\mathrm{Pb}$ bioaccessibility between the peat and urban domains may suggest that bioaccessible $\mathrm{Pb}$ in these domains arises from similar sources, such as atmospheric deposition from urban or industrial emissions. Alternatively, this observation in peat may be coincidental and instead governed by the presence of dissolved organic matter, low $\mathrm{pH}$ and reducing conditions in peat soils that are conducive to higher levels of trace element mobility and bioaccessibility (Appleton et al., 2013; Palmer et al., 2013; Yang et al., 2003).

Regional trends in measured gastric bioaccessible $\mathrm{Pb}$ concentrations are illustrated by Fig. 6B. Higher levels of gastric bioaccessibility are present around the Belfast metropolitan area, along the extent of the NI-ROI border, and also along the northeast coast. In addition to a peat source domain immediately north of this latter coastal location, mining activity occurs in this area (GSNI, 2014), although a $\mathrm{Pb}$ mineralisation domain is not present. Another area where measured bioaccessible $\mathrm{Pb}$ concentrations are high is south of Lough Neagh in proximity to an urban source domain. In general, observed spatial patterns in $\mathrm{Pb}$ bioaccessibility closely align with those observed for elevated $\mathrm{Pb}$ soil concentrations (Fig. 2A), areas of higher Pb solubility (Fig. 5) and also with elevated mineralisation, urban, and peat $\mathrm{Pb}$ source domains (Fig. 6A). These findings may suggest that both diffuse anthropogenic and widespread geogenic $\mathrm{Pb}$ sources are capable of presenting health risks from the oral exposure pathway. 
402 Part IIA of the 1990 Environmental Protection Act (EPA 1990) outlines the statutory obligations in 403 England, Wales and Scotland for assessing potentially contaminated areas of land to determine if sites are fit for proposed land use. At the time of writing no cohesive contaminated land legislative framework has been officially adopted in NI or ROI for assessing potential risks to human health. Guidance on the NI Environment Agency (NIEA) web site directs users to English Environment Agency (EA) publications as official adoption and enforcement of Part 3 of the enacted Waste and Contaminated Land Order (NI) 1997 has yet to occur (NIEA, 2010). The Irish Environmental Protection Agency is currently in the process of developing its own framework.

Toxic elements from some types of anthropogenic pollution may be more bioaccessible than those associated with geogenic sources due to the more soluble phases in which they exist in soil (Appleton et al., 2012b; Cave et al. 2007; Ljung et al., 2007; Cave et al. 2003), although this study also found that $\mathrm{Pb}$ attributed to geogenic sources displayed higher average BAFs than $\mathrm{Pb}$ from other source domains. Despite the knowledge that soluble and anthropogenic forms of pollution in the environment may be more likely to cause harm due to their increased bioavailability and bioaccessibility, sections 3.21 - 3.26 of the 2012 DEFRA guidance for Part IIA of EPA 1990 state that soils hosting widespread geogenic contamination or diffuse anthropogenic pollution should not be regarded as contaminated land. The exception is where strong scientific evidence concludes that significant health risks are being caused or are likely to occur (DEFRA, 2012). This approach is not unique to the UK. For example, a similar regime is in place in Finland, where a Government Decree on the Assessment of Soil Contamination and Remediation Needs (214/2007) (Ministry of the Environment Finland, 2007) states that the assessment process shall regard natural geological concentrations and diffuse anthropogenic pollution as contributing to background concentrations (Jarva et al., 2010). However, such guidance may be misaligned with our knowledge concerning the health effects from oral $\mathrm{Pb}$ exposure in soil, particularly with regard to its non-threshold toxicity (ASTDR, 2007; USEPA, 1988). Gathering more evidence on other risk pathways for Pb exposure such as inhalation would help underpin with more certainty the potential health effects from exposure to low level diffuse anthropogenic pollution or widespread geogenic contamination.

The high solubility of $\mathrm{Pb}$ in surface soils and reduced $\mathrm{Pb}$ concentrations in deep soils in the study area suggests that a portion of elevated $\mathrm{Pb}$ concentrations is from diffuse anthropogenic pollution sources. This finding is supported by the observed spatial trends in $\mathrm{Pb}$ soil distributions where elevated concentrations align with urban and peat source domains. Upland peat soils may be intercepting anthropogenic $\mathrm{Pb}$ carried in rainfall. The medium range spatial structure observed for extractable $\mathrm{Pb}$ concentrations also supports the conclusion that anthropogenic processes may be influencing or have 
historically influenced $\mathrm{Pb}$ soil concentrations. Bioaccessibility in the urban domain was higher than that observed in the remaining rural domain, demonstrating the anthropogenic effects of industrial activity and higher population densities over $\mathrm{Pb}$ distributions and associated possible health effects.

From an oral risk exposure standpoint, the region identified as a mineralisation domain hosted the highest concentrations of bioaccessible $\mathrm{Pb}$. Although the granite domain accounted for lower maximum levels of bioaccessibility compared to the other domains, average BAFs were highest in soils overlying the granite domain. These findings suggesting that risk associated with geogenic sources of $\mathrm{Pb}$ should also be taken into consideration.

\section{Conclusion}

Combining existing knowledge surrounding non-threshold toxicity with the findings that $\mathrm{Pb}$ in the study area displays moderate to high solubility and oral bioaccessibility and warrants more detailed risk evaluation for $\mathrm{Pb}$ in soil. The findings of this study should be taken into account during the development of final $\mathrm{Pb}$ soil screening levels and the adoption of an official Irish or Northern Irish contaminated land regime, if or when such measures take place.

Conclusions regarding toxicity risks from oral soil $\mathrm{Pb}$ exposure can only be made on a site specific basis taking all exposure pathways and relevant land use scenarios into account. However, the findings of this research suggest that diffuse anthropogenic forms of pollution and the presence of natural geogenic contaminants should be considered more carefully in a health risk context, particularly in the case of a non-threshold toxin such as $\mathrm{Pb}$.

\section{Acknowledgements}

2013 UBM testing was supported by the EU INTERREG IVA-funded Tellus Border project. Tellus Border is a $€ 5$ million cross-border project to map the environment and natural resources in the border region of Ireland and continue the analysis of data in the border counties of Northern Ireland. It is a joint initiative between the Geological Survey of Northern Ireland, the Geological Survey of Ireland, Queen's University Belfast and Dundalk Institute of Technology. The views and opinions expressed in this report do not necessarily reflect those of the European Commission or the SEUPB.

The Northern Ireland Tellus project was funded by the Northern Ireland Department of Enterprise, Trade and Investment and by the Rural Development Programme through the Northern Ireland Programme for Building Sustainable Prosperity. 
Special thanks to staff at the Analytical Geochemistry Facility at the BGS Kingsley Dunham Centre, especially Mr. Tom Barlow and Mr. Elliott Hamilton for their invaluable technical and analytical support.

\section{$\underline{\text { References }}$}

Agency for Toxic Substances and Disease Registry (ATSDR) (2007). Toxicological Profile for Lead. United States Public Health Service; Atlanta, GA.

Aitchison, J., 1986. The Statistical Analysis of Compositional Data: Monographs on Statistics and Applied Probability. Chapman \& Hall Ltd., London (UK), p. 416 (Reprinted in 2003 with additional material by The Blackburn Press).

Alloway, B.J., ed. (2012). Heavy Metals in Soils, $3^{\text {rd }}$ edition. Springer Publishing.

Appleton, J.D.; M.R. Cave, J. Wragg (2012a). "Modelling lead bioaccessibility in urban topsoils based on data from Glasgow, London, Northampton and Swansea, UK.” Environmental Pollution 171: 265-272.

Appleton, J.D.; M.R. Cave, J. Wragg (2012b). "Anthropogenic and geogenic impacts on arsenic bioaccessibility in UK topsoils.” Science of the Total Environment 435-436: 21-29.

Appleton, J.D.; M.R. Cave, B. Palumbo-Roe, J. Wragg (2013). "Lead bioaccessibility in topsoils from lead mineralisation and urban domains, UK.” Environmental Pollution 178: 278-287.

BARGE/INERIS (2010). "UBM procedure for the measurement of inorganic contaminant bioaccessibility from solid matrices.” Downloaded from http://www.bgs.ac.uk/barge/ubm.html.

Barsby, A.; J.M. McKinley, U. Ofterdinger, M. Young, M.R. Cave, J. Wragg (2012). "Bioaccessibility of trace elements in soils in Northern Ireland." Science of the Total Environment 433: 398-417.

Bourennane, H.; F. Douay, T. Sterckeman, E. Villanneau, H. Ciesielski, D. King, D. Baize (2010). "Mapping of anthropogenic trace elements inputs in agricultural topsoil from Northern France using enrichment factors.” Geoderma 157: 165-174.

Brown, P.A., Gill, S.A., Allen, S.J., 2000. Metal removal from wastewater using peat. Water Res. 34, 3907 e3916.

Caboche, J. (2009). "Validation d'un test de mesure de bioaccessibilité. Application à quatre éléments traces métallique dans les sols: As, $\mathrm{Cd}, \mathrm{Pb}$ et Sb.” Science Agronomique. PhD. L'Institut National Polytechnique de Lorraine, Nancy, pp. 348.

Canadian Council of Ministers of the Environment (CCME) (1999). “Lead.” Canadian Soil Quality Guidelines for the Protection of Environmental and Human Health. 
Cave, M.; H. Taylor, J. Wragg (2007). "Estimation of the bioaccessible arsenic fraction in soils using near infrared spectroscopy.” Journal of Environmental Science and Health Part A, 1293-1301.

Cave, M.R.; J. Wragg, B. Palumbo, B.A. Klinck (2003). Measurement of the bioaccessibility of arsenic in UK soils. Environment Agency R\&D Technical Report P5-062/TR02.

Central Statistics Office (CSO) (2011). "Population of Each Province, County and City, 2011.” Viewed at www.cso.ie/en/statistics.

The Chartered Institute of Environmental Health (CIEH) (2009). "Reviewing human health risk assessment reports invoking contaminant oral bioavailability measurements or estimates." Professional practice note available at http://www.cieh.org.

Clarke, I. (2001). Practical Geostatistics. Pdf downloaded from www.kriging.com on $5^{\text {th }}$ March 2012.

Cohen, D. R.; N.F. Rutherford, E. Morisseau, A.M. Zissimos (2012). "Geochemical patterns in the soils of Cyprus." Science of the Total Environment 420: 250-262. DOI: 10.1016/ j.scitotenv.2012.01.036

Coulter, S.; J. Stinson (2013). A Preliminary Prospectivity Map for the Tellus Border region. Final Project Report. Viewed at http://www.tellusborder.eu/NR/rdonlyres/89DD2F70-766D-49F9-A5B32DDCE5763CFA/0/Coulter_Stinson_prospectivity.pdf.

Cox, S.F., M. Chelliah, J.M. McKinley, S. Palmer, U. Ofterdinger, M.R. Cave, J. Wragg, M. Young. "The importance of solid-phase distribution on the oral bioaccessibility of $\mathrm{Ni}$ and $\mathrm{Cr}$ in soils overlying Palaeogene basalt lavas, Northern Ireland.” Environmental Geochemistry and Health 35(5): 553-567.

Department for Environment, Food and Rural Affairs (DEFRA) (2012). Environmental Protection Act 1990: Part 2A. Contaminated Land Statutory Guidance. HM Government, Her Majesty’s Stationery Office.

DEFRA \& Environment Agency (EA) (2002a). Assessment of Risks to Human Health from Land Contamination: An Overview of the Soil Guideline Values and Related Research. R\&D Publication CLR 7. Withdrawn.

DEFRA \& EA (2002b). Contaminants in Soil: Collation of toxicological data and intake values for humans. Lead, R\&D Publication TOX 6. Withdrawn.

Delgado, M. R.; J. Parsons, G. Humberto, A. Corral, G.J. Cruz, A.T. Campos, A.M. Duarte, J. Gardea-Torresday (2011). "Comparison of ICP-OES and XRF performance for $\mathrm{Pb}$ and As Analysis in Environmental Soil Samples from Chihuahua City, Mexico.” Physical Review \& Research International 1(2): 29-44.

Denys, S.; J. Caboche, K. Tack, G. Rychen, J. Wragg, M. Cave, C. Jondreville, C. Feidt (2012). “In vivo validation of the unified BARGE method to assess the bioaccessibility of arsenic, antimony, cadmium and lead in soils.” Environmental Science and Technology 46: 6252-6260. 
Denys, S.; J. Caboche, K. Tack, P. Delalain (2007). "Bioaccessibility of lead in high carbonate soils." Journal of Environmental Science and Health Part A, 1331-1339.

Dobermann, A.; P. Gooaverts, T. George (1995). "Sources of soil variation in an acid Ultisol of the Philippines.” Geoderma 68: 173-191.

Einax, J.W.; U. Soldt (1999). "Geostatistical and multivariate statistical methods for the assessment of polluted soils-merits and limitations." Chemometrics and Intelligent Laboratory Systems 46: 7991.

EA (2009). Human health toxicological assessment of contaminants in soil. Science Report - Final SC050021/SR2.

EA (2007). UK Soil and Herbage Pollutant Survey. UKSHS Report No. 7. Environmental concentrations of heavy metals in UK soil and herbage.

Environmental Protection Act 1990 (EPA 1990), Pt IIA, “Contaminated Land.”

Environmental Standards Research Institute (ESRI) (2010) ArcGIS, ArcMap and ArcCatalogue 10.0 geographical information systems software and help files.

European Environment Agency (2012). Corine land cover 2006 seamless vector data. Version 16 (04/2012). http://www.eea.europa.eu/data-and-maps/data/clc-2006-vector-data-version-3.

European Food Safety Authority (EFSA) (2010). “Scientific opinion on lead in food.” EFSA Journal 8(4): 1570.

Farmer, J.G.; A. Broadway, M.R. Cave, J. Wragg, F.M. Fordyce, M.C. Graham, B.T. Ngwenya, R. Bewley (2011). "A lead isotopic study of the human bioaccessibility of lead in urban soils from Glasgow, Scotland.” Science of the Total Environment 409: 4958-4965.

Fealy, R.; S. Green (2009). Teagasc-EPA Soils and Subsoils Mapping Project Final Report. Dublin.

Finžgar, N.; P. Tlustoš, D. Leštan (2007). "Relationship of soil properties to fractionation, bioavailability and mobility of lead and zinc in soil.” Plant Soil and Environment 53: 225-238.

Geological Survey of Ireland (GSI). (2005). 1:500000 Bedrock Geology Map. Retrieved from http://www.dcenr.gov.ie/Spatial+Data/Geological+Survey+of+Ireland/GSI+Spatial+Data+Downloads .htm

Geological Survey of Northern Ireland (GSNI) (2014). “Enquiries: Historic mine workings” and "Minerals: Active quarries." Data layers viewed on GeoIndex at http://mapapps2.bgs.ac.uk/ GSNI_Geoindex/home.html.

Gill, R. ed., (1997). Modern Analytical Geochemistry, Addison Wesley Longman.

Goulard, M.; M. Voltz (1992). "Linear coregionalization model: tools for estimation and choice of cross-variogram matrix.” Mathematical Geology 24(3): 269-286. 
Harries, N; M. Quint, S. Firth, E. Stutt, S. Bull, C. Pease, A. Hart, R. Macarthur, M. Kennedy, S. Moreby (2013). SP1010 - Development of Category 4 Screening Levels for Assessment of Land

Imrie, C.E., A. Korre, G. Munoz-Melendez, I. Thornton, S. Durucan (2008). "Application of factorial

Jarva, J.; T. Tarvainen, P. Lintinen, J. Reinikainen (2009). "Chemical Characterization of MetalContaminated Soil in Two Study Areas in Finland.” Water, Air, and Soil Pollution 198: 373-391. DOI: 10.1007/s11270-008-9852-3

Jarva, J.; T. Tarvainen, J. Reinikainen, M. Eklund (2010). “TAPIR - Finnish national geochemical baseline database.” Science of the Total Environment 408: 4385-4395.

Jordan, C.; A. Higgins, K. Hamill, J.G. Cruickshank (2001). The Soil Geochemical Atlas of Northern Ireland. Department of Agriculture and Rural Development, NI.

Jordan, C.; C. Zhang, A. Higgins (2007). "Using GIS and statistics to study influences of geology on probability features of surface soil geochemistry in Northern Ireland.” Journal of Geochemical Exploration 93, 135-152.

Knights, K.V.; M.M. Glennon (2013). Tellus Border Project Geochemical Data User Guide v.1. Geological Survey of Ireland and Geological Survey of Northern Ireland joint report.

Krauskopf, K.B. (1967). Introduction to Geochemistry. McGraw-Hill, New York.

Lee, T.; C.L Yao (1970). "Abundance of chemical elements in the earth's crust and its major tectonic units.” International Geology Review 12(7): 778-786.

Ljung, K.; A. Oomen, M. Duits, O. Selinus, M. Berglund (2007). "Bioaccessibility of metals in urban playground soils.” Journal of Environmental Science and Health Part A 42, 1241-1250.

Ljung, K.; O. Selinus, E. Otabbong, M. Berglund (2006). "Metal and arsenic distribution in soil particle sizes relevant to soil ingestion by children.” Applied Geochemistry 21: 1613-1624.

Lloyd, C.D. (2010). Spatial Data Analysis: An Introduction for GIS Users. Oxford University Press.

Lusty, P., C. Scheib, A. Gunn, A. Walker (2012). "Reconnaissance-scale prospectivity analysis for gold mineralisation in the Southern Uplands-Down-Longford Terrane , Northern Ireland”. Natural Resources Research, 21(3), 359-382.

Matheron, G. (1965). Les variables régionalisées et leur estimation. Paris: Masson. 
McBratney, A.B.; R. Webster, R.G. McLaren, R.B. Spiers (1982). "Regional variation of extractable copper and cobalt in the topsoil of south-east Scotland.” Agronomie 2(10): 969-982.

McIlwaine, R., S.F. Cox, R. Doherty, S. Palmer, U. Ofterdinger, J. McKinley (2014). "Comparison of methods used to calculate typical threshold values for potentially toxic elements in soil." Environmental Geochemistry and Health DOI:10.1007/s10653-014-9611-x.

Met Office, 2012. Northern Ireland: Climate. Viewed at: http://www.metoffice.gov. uk/climate/uk/ni/print.html.

Mielke, H. W.; S. Zahran (2012). "The urban rise and fall of air lead (Pb) and the latent surge and retreat of societal violence.” Environment International 43: 48-55.

Ministry of the Environment Finland. (2007). Government Decree on the Assessment of Soil Contamination and Remediation Needs (214/2007).

Nathanail, C.P. (2006). "Generic and site-specific criteria in assessment of human health risk from

Nathanail, C.P.; R. Smith (2007). "Incorporating bioaccessibility in detailed quantitative human health risk assessments.” Journal of Environmental Science and Health Part A 42, 1193-1202.

Nevin, R. (2000). "How lead exposure relates to temporal changes in IQ, violent crime, and unwed pregnancy.” Environmental Research: 83(1), 1-22.

Nevin, R. (2007). “Understanding international crime trends: the legacy of preschool lead exposure.” Environmental Research: 104(3), 315-336.

Northern Ireland Environment Agency (2010). "Land Quality” and associated web pages at http://www.doeni.gov.uk/niea/land-home/land-quality.htm. Accessed $20^{\text {th }}$ March, 2014. Last updated $11^{\text {th }}$ May 2010.

Nriagu, J.O.; J. Pacyna (1989). "Quantitative assessment of worldwide contamination of air, water and soils by trace metals.” Nature 333:134-139.

Office for National Statistics (ONS) (2013). "Population Estimates for UK, England and Wales, Scotland and Northern Ireland, Mid-2001 to Mid-2010 Revised.” Viewed at Www.ons.gov.uk, released $17^{\text {th }}$ December 2013.

Palmer, S.; U. Ofterdinger, J.M. McKinley, S. Cox, A. Barsby (2013). "Correlation analysis as a tool to investigate the bioaccessibility of nickel, vanadium and zinc in Northern Ireland soils." Environmental Geochemistry and Health 35(5): 569-584.

Pawlowsky-Glahn, V., Buccianti, A. (Eds.), 2011. Compositional Data Analysis: Theory and Applications. John Wiley \& Sons, Chichester, pp. 12e28.

R Core Team. (2013). R: A Language and Environment for Statistical Computing. Vienna, Austria: R Foundation for Statistical Computing. Retrieved from http://www.r-project.org. 
Rose, A.W.; H.E. Hawkes, J.S. Webb (1979). Geochemistry in Mineral Exploration, $2^{\text {nd }}$ edition. Academic Press, London.

Rosen, J.F. (1995). “Adverse health effects of lead at low exposure levels: trends in the management of childhood lead poisoning.” Toxicology 97: 11-17.

Ruby, M.V.; R . Schoof, W. Brattin, M. Goldade, G. Post, M. Harnois, D.E. Mosby, S.W. Casteel, W. Berti, M. Carpenter, D. Edwards, D. Cragin, W. Chappell (1999). "Advances in Evaluating the Oral Bioavailability of Inorganics in Soil for Use in Human Health Risk Assessment." Environmental Science \& Technology 33 (21), 3697-3706.

Ryan, J.A.; K.G. Scheckel, W.R. Berti, S.L. Brown, S.W. Casteel, R.L. Chaney, J. Hallfrisch, M. Doolan, P. Grevatt, M. Maddaloni, D. Mosby (2004). "Reducing children's risk from lead in soil." Environmental Science and Technology, January $1^{\text {st }}$.

Scheckel, K.G., R.L. Chaney, N.T. Basta, J.A. Ryan (2009). "Advances in assessing the bioavailability of metal(loid)s in contaminated soils.” Advances in Agronomy 104.

Smyth, D. (2007). Methods used in the Tellus geochemical mapping of Northern Ireland. British Geological Survey Open Report OR/07/022, 2007.

Steinnes, E., Friedland, A.J., 2006. Metal contamination of natural surface soils from long-range atmospheric transport: existing and missing knowledge. Environ. Rev. 14, 169e186.

Taylor, S.R. (1964). "Abundance of chemical elements in the continental crust, a new table." Geochimica et Cosmochimica Acta 28(8): 1273-1285.

The United States Environmental Protection Agency (USEPA) (1988). "Lead and compounds (inorganic), CASRN 7439-92-1. Reference dose (RfD) for chronic oral exposure.” 1988 RfD Statement viewed at http://www.epa.gov/iris/subst/0277.htm, page last updated January 24 ${ }^{\text {th }}, 2013$.

USEPA (2013) "Human health and lead.” Accessed at http://www.epa.gov/superfund/lead/health. htm, page last updated November $25^{\text {th }} 2013$.

Van De Weile, T.R., A.G. Oomen, J. Wragg, M. Cave, M. Minekus, A. Hack, C. Cornelis, C. Rompleberg, L.L. De Zwart, B. Klinck, J. Van Wijnen, W. Verstraete, A. Sips (2007). "Comparison of five in vitro digestion models to in vivo experimental results: Lead bioaccessibility in the human gastrointestinal tract.” Journal of Environmental Science and Health Part A 42, 1203-1211.

Wragg, J. (2009). BGS guidance material 102, ironstone soil, certificate of analysis. British Geological Survey, Keyworth, Nottingham.

Wragg, J.; M. Cave, N. Basta, E. Brandon, S. Casteel, S. Denys, C. Gron, A. Oomen, K. Reimer, K. Tack, T. Van de Wiele (2011). "An inter-laboratory trial of the unified BARGE bioaccessibility method for arsenic, cadmium and lead in soil.” Science of the Total Environment 409: 4016-4030. 
753 Yang, J.K.; M.O. Barnett, P.M. Jardine, S.C. Brooks (2003). "Factors controlling bioaccessibility of 754 arsenic(V) and lead(II) in soil.” Soil \& Sediment Contamination 12(2): 165-179.

755

756 Zhang, C. (2006). "Using multivariate analyses and GIS to identify pollutants and their spatial 757 patterns in urban soils in Galway, Ireland.” Environmental Pollution 142, 501-511.

758

759 


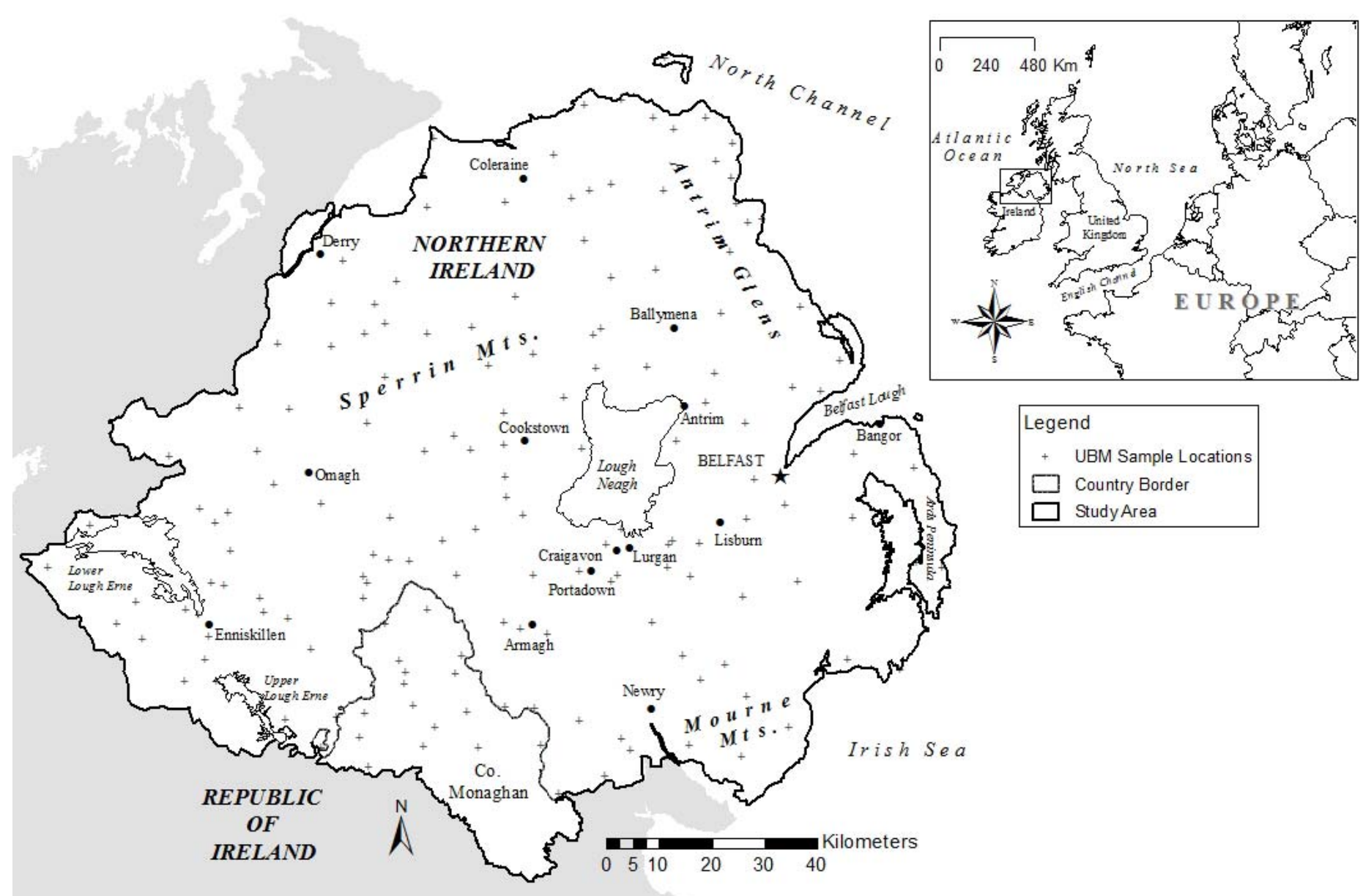

763 Fig. 1 Study area map showing location in Europe and 163 UBM sample locations across Northern Ireland and Co. Monaghan in the Republic of Ireland 764 (ROI); Northern Ireland images are GSNI Crown Copyright 


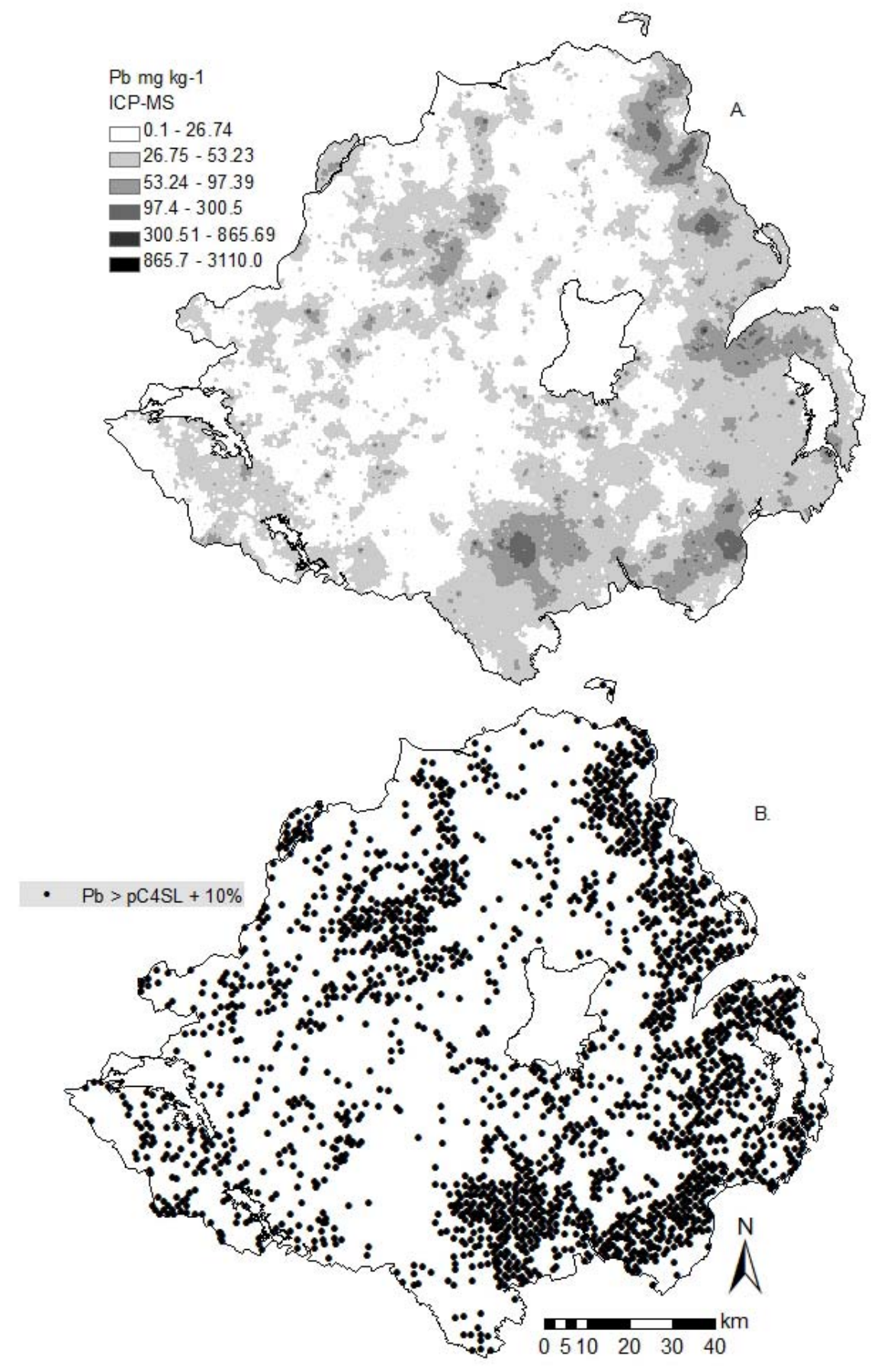

766

767 Fig. 2 (A) ICP-MS Pb concentrations ( $\mathrm{mg} \mathrm{kg}^{-1}$ ) in 'A' soils across study area and (B) soil sample

768 locations from NI Tellus and Tellus Border geochemical surveys where 'A' soil concentrations

769 exceed the lowest published pC4SL of $30 \mathrm{mg} \mathrm{kg}^{-1}$ by $10 \%$ or greater $(n=2,208)$ for a female child 770 receptor in an allotment setting (Harries et al., 2013) 


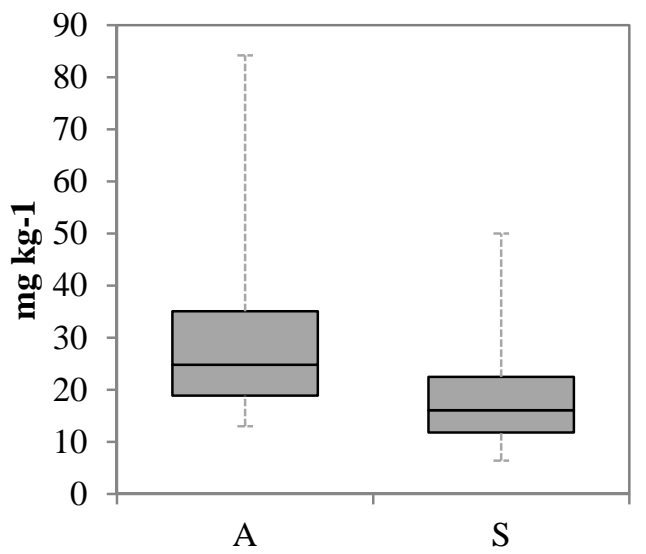

772

773 Fig. 3 Surface ('A') Pb extractable concentrations versus beneath-surface ('S') Pb extractable

774 concentrations as measured by ICP-MS following an aqua regia digest in Northern Ireland. Lower

775 and upper error bars represent $5^{\text {th }}$ and $95^{\text {th }}$ percentile ranges, respectively.

776

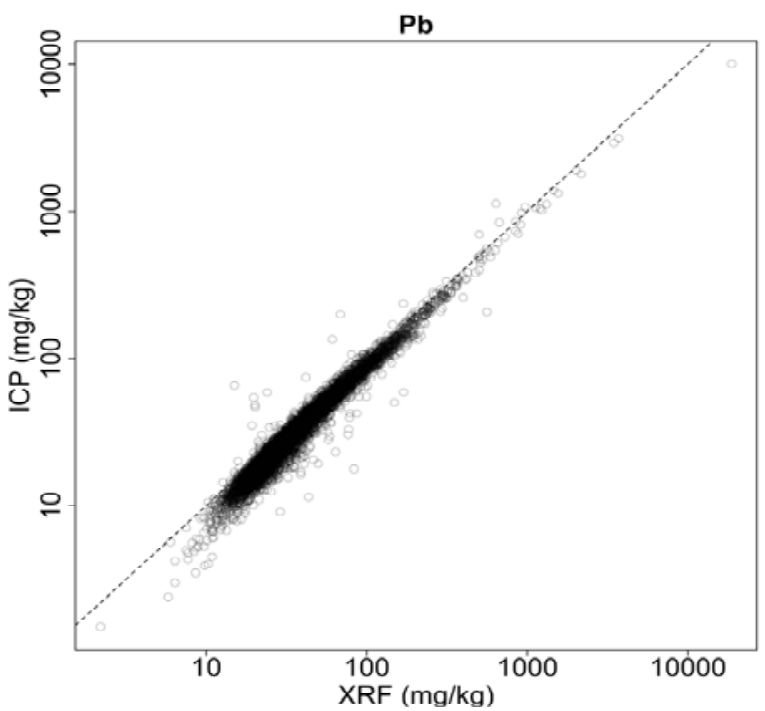

778 Fig. $4 \mathrm{~Pb}$ extractable concentrations in 'A' soils measured by ICP-MS plotted against total Pb XRFS

779 concentrations in NI and Co. Monaghan; dashed line indicates a 1-1 ratio between the two 780 concentrations 


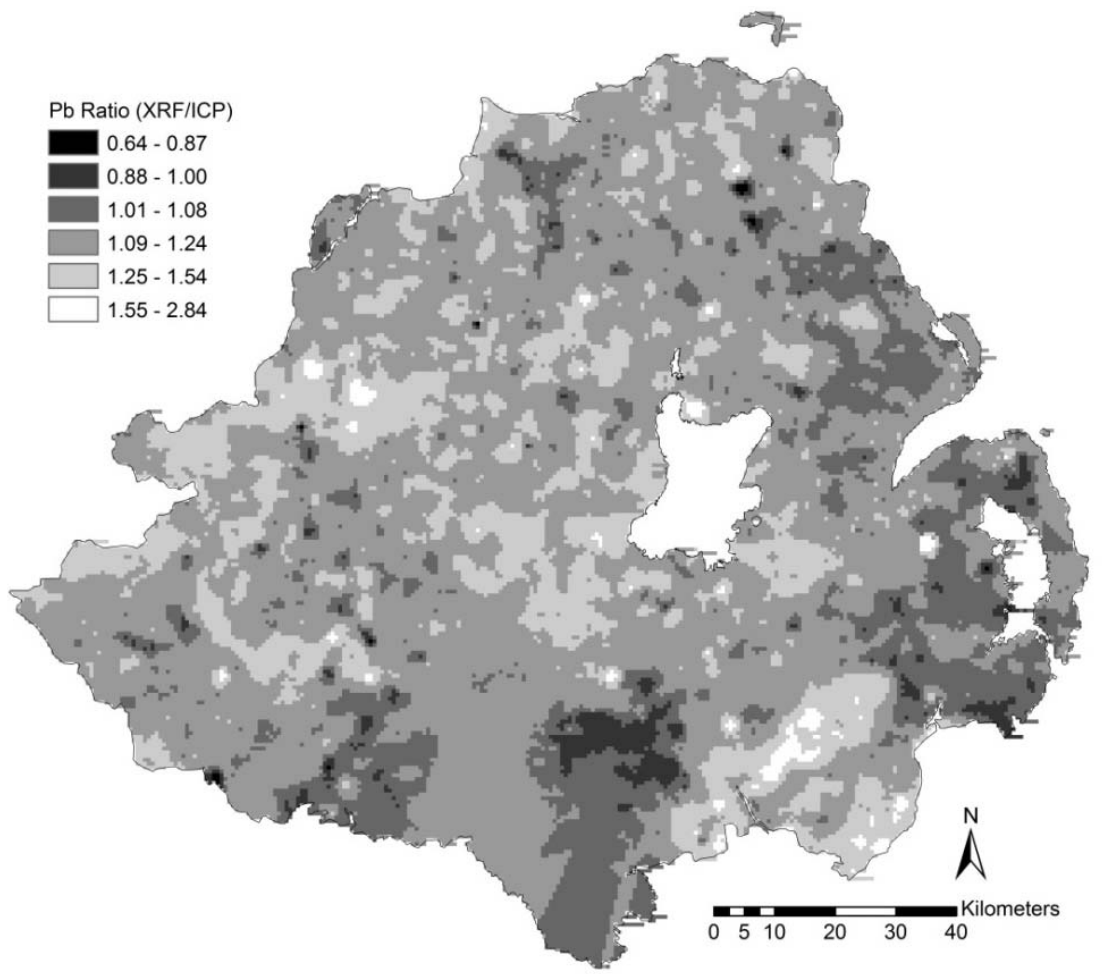

783 Fig. 5 Map of XRFS total-ICP extractable Pb concentrations; high ratios illustrate areas of lower $\mathrm{Pb}$

784 solubility and low ratios illustrate where high $\mathrm{Pb}$ solubility exists 


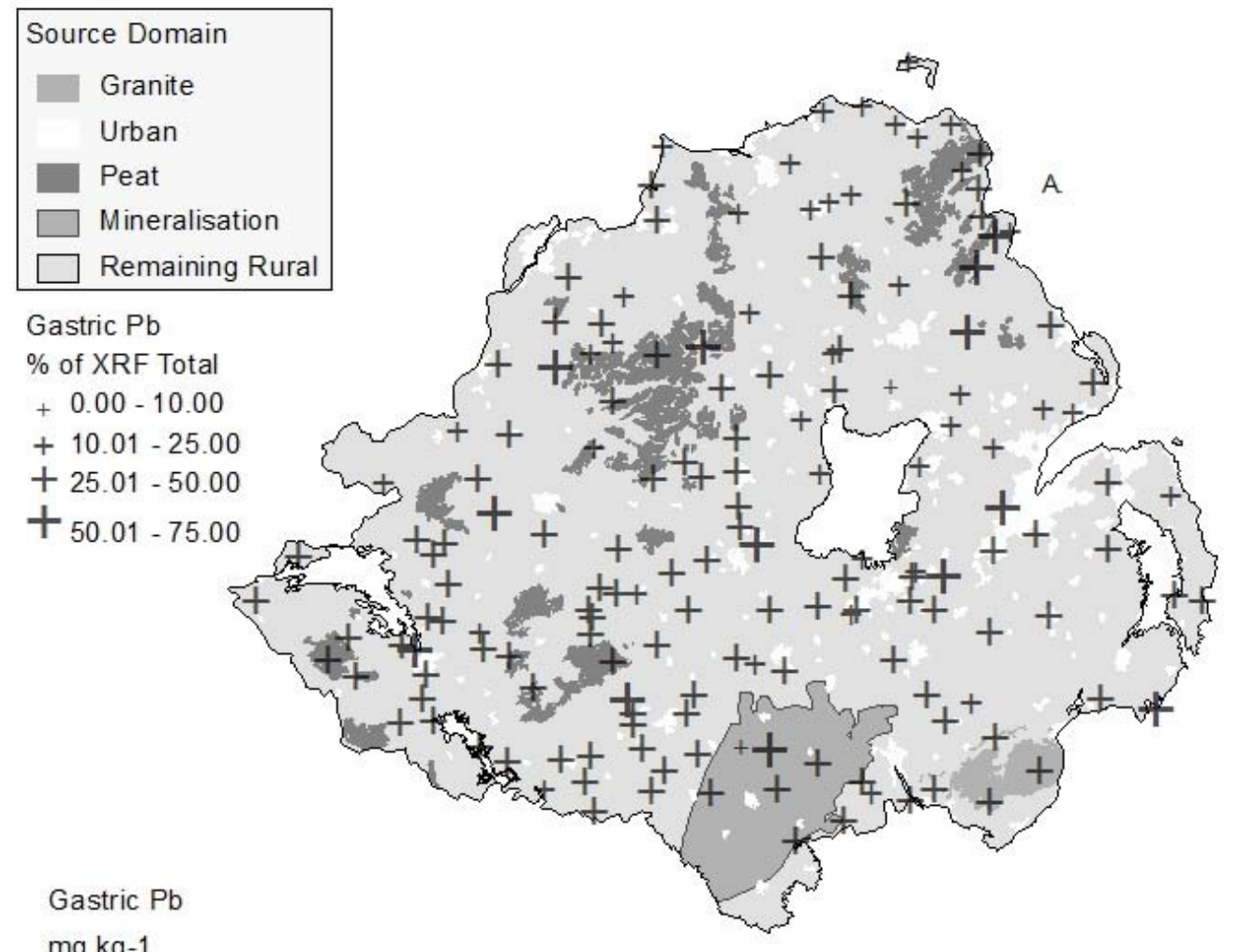

$\mathrm{mg} \mathrm{kg}-1$

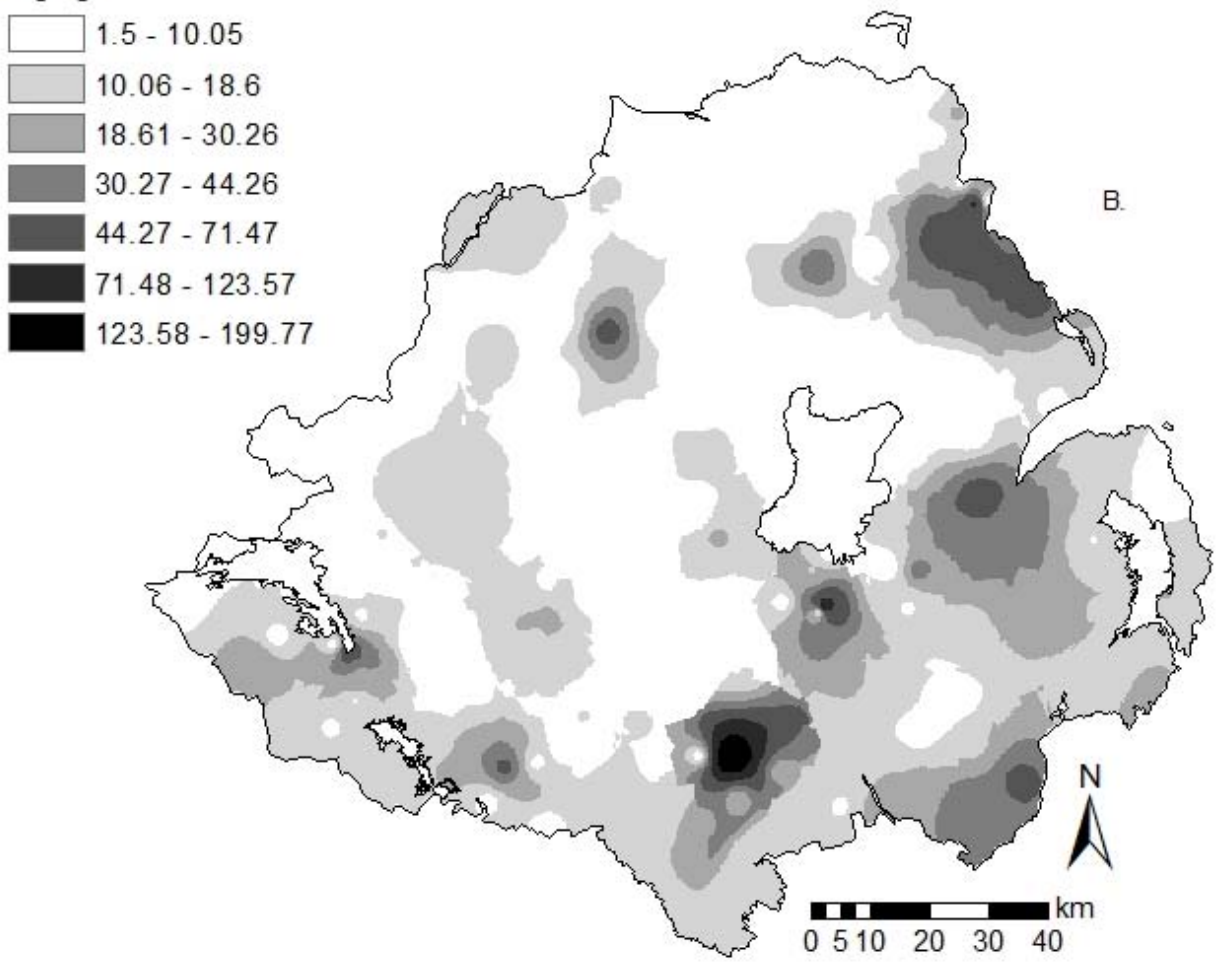

Fig. 6 (A) Elevated Pb source domains within study area identified by ECDF method overlain with measured $\mathrm{Pb} \mathrm{G}$ BAFs expressed as percentage of total XRFS concentrations and (B) $\mathrm{Pb}$ oral bioaccessibility (mg kg-1 $)$ interpolated by IDW, 5 nearest neighbours; $n=163$ 
Tables

Table $1 \mathrm{pH}$ tolerances for stabilised UBM digestive fluids

\begin{tabular}{cc}
\hline Solution & $\mathrm{pH}$ Tolerance \\
\hline Saliva & $6.5+/-0.5$ \\
Gastric & $1.0+/-0.1$ \\
Duodenal & $7.4+/-0.2$ \\
Bile & $8.0+/-0.2$ \\
\hline
\end{tabular}

797

798

799

Table 2 Summary of study area and sample set ' $\mathrm{A}$ ' soil Pb concentrations compared against historic and provisional generic UK soil assessment criteria and study area typical threshold values (TTVs);

801 all values in $\mathrm{mg} \mathrm{kg}^{-1}$

\begin{tabular}{|c|c|c|c|c|c|c|c|c|c|c|}
\hline \multirow{3}{*}{$\begin{array}{c}\text { Historic UK } \\
\mathrm{SGV}^{\mathrm{a}}\end{array}$} & \multirow{3}{*}{$\mathrm{pC} \mathrm{SL}^{\mathrm{b}}$} & \multirow{3}{*}{\multicolumn{2}{|c|}{$\begin{array}{c}\text { Study Area } \\
\text { Source Domain } \\
\text { TTVs }^{\mathrm{c}}\end{array}$}} & \multicolumn{7}{|c|}{$\mathrm{Pb}$ ‘A’ Soil Concentrations } \\
\hline & & & & \multicolumn{4}{|c|}{$\begin{array}{l}\text { Study Area } \\
n=7,234^{\mathrm{d}}\end{array}$} & \multicolumn{3}{|c|}{$\begin{array}{l}\text { Study Sample Set } \\
\qquad n=163^{\mathrm{e}}\end{array}$} \\
\hline & & & & Method & Mean & Med & Max & Mean & Med & Max \\
\hline \multicolumn{2}{|c|}{ Res/Allot } & Mineral & Granite & \multirow[b]{2}{*}{ XRFS } & \multirow[b]{2}{*}{41.6} & \multirow[b]{2}{*}{28.8} & \multirow[b]{2}{*}{18,756} & \multirow[b]{2}{*}{39.8} & \multirow[b]{2}{*}{28.7} & \multirow[b]{2}{*}{291.0} \\
\hline 450 & $30-330$ & 110 & 170 & & & & & & & \\
\hline \multirow{2}{*}{\multicolumn{2}{|c|}{ Commercial }} & Peat & Urban & & & & & & & \\
\hline & & 160 & 220 & ICP-MS & 31.5 & 23.2 & 3,110 & 35.4 & 23.5 & 268.0 \\
\hline
\end{tabular}

63

${ }^{\mathrm{a}}$ DEFRA \& EA, $2002 a$ \& $2002 b$

${ }^{\mathrm{b}}$ Range of values dependent on different modelled exposure and land use scenarios as presented in Harries et al. $(2013)$. Res = residential, allot $=$ allotment.

${ }^{\mathrm{c}}$ The unique values calculated for this study incorporating 18 sample locations in Co. Monaghan did not yield different TTV results from McIlwaine et al., 2014. Mineral = mineralisation domain.

${ }^{\mathrm{d}}$ Based on NI Tellus and Tellus Border geochemical survey data where 7,234 samples were analysed by ICP-MS in NI and Co. Monaghan. 6,862 were analysed by XRFS in NI with 18 additional samples in Co. Monaghan analysed by XRFS outside of routine Tellus Border survey analyses.

${ }^{\mathrm{e}}$ Inclusive of 90 samples from Barsby et al., 2012

Table $3 \mathrm{~Pb}$ geostatistical summary showing 98\% of total variance in $\mathrm{Pb}$ extractable soil distributions is accounted for by a short-range function as modelled in Fig. 2 while total concentrations show $\mathrm{Pb}$ concentrations are controlled by a longer range function suggestive of geogenic processes

\begin{tabular}{lccccc}
\hline & $\begin{array}{c}\text { Nugget } \\
\text { Variance } \\
C_{o}\end{array}$ & $\begin{array}{c}\text { Function } \\
\text { Variance } \\
C_{1}\end{array}$ & $\begin{array}{c}\text { Range } \\
(\mathrm{km}) \\
a\end{array}$ & $\begin{array}{c}\text { Total } \\
\text { Variance } \\
C=C_{0}+C_{1}\end{array}$ & $\begin{array}{c}\text { Unexplained } \\
\text { Variance }\end{array}$ \\
\hline Extractable $\mathrm{Pb}$ (ICP) & 0.004 & 0.197 & 1.2 & 0.201 & $\left(C_{o} / C_{1}\right) * 100$ \\
\hline & & & & & $2 \%$ \\
Total Pb (XRFS) & 0.193 & 0.100 & 32.9 & 0.293 & $66 \%$ \\
XRFS/ICP Ratio & 0.004 & 0.014 & 3.5 & 0.018 & $21 \%$ \\
\hline
\end{tabular}


Table 4 Summary of gastric (G) and gastro-intestinal (GI) Pb bioaccessible concentrations (mg kg-1)

819 and bioaccessible fractions (BAF, \%) in study area $(n=163)$

\begin{tabular}{cccccccccc}
\hline & \multicolumn{3}{c}{$\mathrm{mg} \mathrm{kg}^{-1}$} & \multicolumn{4}{c}{ XRFS-BAF } & \multicolumn{3}{c}{ ICP-BAF } \\
\hline & Med & Max & Min & Med & Max & Min & Med & Max & Min \\
\cline { 2 - 10 } G Pb & 8.6 & 199.8 & 1.5 & 33.9 & 68.6 & 8.2 & 40.3 & 74.6 & 9.7 \\
GI Pb & 3.8 & 85.9 & 0.0 & 12.8 & 35.1 & 0.2 & 15.6 & 38.1 & 0.3
\end{tabular}

822 Table 5 Comparison of $\mathrm{Pb} \mathrm{G}$ bioaccessible concentrations ( $\mathrm{mg} \mathrm{kg}^{-1}$ ) and BAF (\%) against identified $823 \mathrm{~Pb}$ concentrations in 'A' soils overlying five $\mathrm{Pb}$ source domains in study area

\begin{tabular}{ccccccccccc}
\hline \multirow{2}{*}{ Domain } & \multicolumn{3}{c}{ G Pb } & \multicolumn{4}{c}{ ICP-BAF } & \multicolumn{4}{c}{ XRFS-BAF } \\
& Mean & Max & Min & Mean & Max & Min & Mean & Max & Min \\
\hline $\begin{array}{c}\text { Mineralisation } \\
n=9 \\
\begin{array}{c}\text { Granite } \\
n=3\end{array}\end{array}$ & 36.4 & 199.8 & 6.9 & 42.7 & 74.6 & 15.8 & 37.3 & 68.6 & 8.2 \\
$\begin{array}{c}\text { Peat Soil } \\
n=18\end{array}$ & 20.6 & 74.9 & 49.0 & 16.3 & 46.4 & 52.2 & 37.5 & 40.2 & 46.8 & 34.4 \\
$\begin{array}{c}\text { Urban } \\
n=31\end{array}$ & 19.9 & 97.6 & 2.3 & 42.6 & 66.2 & 13.4 & 37.3 & 64.4 & 12.3 \\
$\begin{array}{c}\text { Remaining Rural } \\
n=102\end{array}$ & 9.7 & 51.3 & 1.5 & 35.6 & 65.8 & 9.7 & 30.5 & 58.9 & 9.8 \\
\hline
\end{tabular}

824 